\title{
Antimicrobial resistance of bacterial enteropathogens isolated from stools in Madagascar
}

Frederique Randrianirina ${ }^{1 \dagger}$, Elisoa Hariniana Ratsima ${ }^{1 \dagger}$, Lova Ramparany $^{1}$, Rindra Randremanana ${ }^{2}$, Hanitra Clara Rakotonirina ${ }^{3}$, Tahiry Andriamanantena ${ }^{3}$, Fanjasoa Rakotomanana², Soatiana Rajatonirina², Vincent Richard ${ }^{2}$ and Antoine Talarmin ${ }^{*}$

\begin{abstract}
Background: Diarrheal diseases are a major public health problem in developing countries, and are one of the main causes of hospital admissions in Madagascar. The Pasteur Institute of Madagascar undertook a study to determine the prevalence and the pathogenicity of bacterial, viral and protozoal enteropathogens in diarrheal and non-diarrheal stools of children aged less than 5 years in Madagascar. We present here the results of the analysis of antimicrobial susceptibility of the bacteria isolated during this study.

Methods: The study was conducted in the community setting in 14 districts of Madagascar from October 2008 to May 2009. Conventional methods and PCR were used to identify the bacteria; antimicrobial susceptibility was determined using an agar diffusion method for enterobacteriaceae and MICs were measured by an agar dilution method for Campylobacter sp. In addition to the strains isolated during this study, Salmonella sp and Shigella sp isolated at the Pasteur Institute of Madagascar from 2005 to 2009 were included in the analysis to increase the power of the study.
\end{abstract}

Results: Twenty-nine strains of Salmonella sp, 35 strains of Shigella sp, 195 strains of diarrheagenic E. coli, 203 strains of $C$. jejuni and 71 strains of $C$. coli isolated in the community setting were tested for antibiotic resistance. Fifty-five strains of Salmonella sp and 129 strains of Shigella sp isolated from patients referred to the Pasteur Institute of Madagascar were also included in the study. Many E. coli and Shigella isolates (around 80\%) but fewer Salmonella isolates were resistant to ampicillin and trimethoprim/sulfamethoxazole. A small proportion of strains of each species were resistant to ciprofloxacin and only $3 \%$ of $E$. coli strains presented a resistance to third generation cephalosporins due to the production of extended-spectrum beta-lactamases. The resistance of Campylobacter sp to ampicillin was the most prevalent, whereas less than $5 \%$ of isolates were resistant to each of the other antibiotics.

Conclusion: The highest prevalence of antimicrobial resistance was to ampicillin and trimethoprim/ sulfamethoxazole. Antibiotic treatment is not recommended for children with diarrhea in Madagascar and the emphasis should be placed on oral rehydration.

Keywords: Antibiotic susceptibility, Bacterial pathogens, Madagascar, Diarrhea

\footnotetext{
* Correspondence: atalarmin@pasteur-guadeloupe.fr

${ }^{\dagger}$ Equal contributors

${ }^{4}$ Institut Pasteur de Madagascar, Antananarivo, Madagascar

Full list of author information is available at the end of the article
} 


\section{Background}

Diarrheal diseases are a major public health problem in developing countries, especially in Africa [1,2]. More than 1.8 million children under 5 years of age die of diarrheal disease every year [2].

The agents capable of causing infectious diarrhea include a wide variety of bacteria, viruses, and parasites. Treatment includes rehydration and in some cases antimicrobial therapy. The acute diarrheal diseases for which antimicrobial therapy is recommended include shigellosis, campylobacteriosis and infection with Vibrio cholerae, $V$. parahaemolyticus and $V$. vulnificus [3,4]. Improving our knowledge of antimicrobial resistance among enteric pathogens is of particular importance in the developing world, where the rate of diarrheal diseases is highest. The continuous increase in antimicrobial resistance among enteric pathogens in developing countries is becoming a serious concern. However, resistance patterns are often regionspecific, and are only very poorly documented in Africa. The data available relating to antimicrobial resistance in bacteria responsible for diarrheal disease in Madagascar is limited. Few studies have described resistance patterns of Shigella, and the most recent was more than 20 years ago [5]; we found no reports concerning the antimicrobial resistance Salmonella, Campylobacter or diarrheagenic Escherichia coli in Madagascar.

The Pasteur Institute of Madagascar recently launched a program to determine the prevalence and the pathogenicity of bacterial, viral and protozoal enteropathogens in diarrheal and non-diarrheal stools of children less than 5 years of age, in 14 different districts of Madagascar [6]. Here, we present an analysis of the antimicrobial resistance of pathogens isolated in this study and of enteric pathogens isolated from the stools of patients referred to the Pasteur Institute of Madagascar for diarrheal disease.

\section{Methods}

\section{Patients enrolled during the multicenter study}

The study was conducted in 14 districts of Madagascar as previously described (Figure 1) [6], from October 2008 to May 2009 during the rainy season, for three consecutive weeks at each site. The study was carried out in the community setting, not in hospitals or health centers. A mobile laboratory well equipped (fridge, incubator, Bunsen, microscope), installed in a four-wheel drive truck, was used for the laboratory procedures in optimal field conditions as soon as the stools were emitted. A generator was used to maintain the electricity when the engine was stopped. Temperatures of the fridge and the incubator were controlled using an electronic thermometer. To avoid contamination, stools were processed one by one near the flame of the Bunsen.

Participants were randomly selected from children less than 5 years of age in several villages in each district.
Participants provided clinical and epidemiological data and a fecal sample for identification of bacterial, viral and protozoal enteropathogens.

Diarrheic patients were children less than five years of age with acute diarrhea (emission of three or more unformed stools within a $24 \mathrm{~h}$ period) without current treatment. After emission of stools, all case patients received treatment according to the World Health Organisation guidelines for diarrheal disease [7].

Non diarrheic subjects were children under five years of age with no history of diarrhea in the previous 3 months and were enrolled at the same time as case subjects (one control for every three cases). Information on demographic and historical clinical data were obtained from parents of both cases and controls and recorded in questionnaires. There was no follow-up after the initial recruitment of patients.

\section{Patients referred to the Pasteur Institute}

Retrospective data concerning the resistance to antibacterial drugs of strains of Salmonella and Shigella isolated from patients referred to the Pasteur Institute from 2005 to 2009 were analysed in the study to increase the number of strains and give a more complete view of the resistance to antibacterial drugs in these species circulating in Madagascar. For these patients fresh stools were brought directly by the patients or their family to the Pasteur Institute and were processed within 2 hours after reception.

\section{Laboratory procedures}

\section{Bacterial isolation and identification}

Bacteria, including Salmonella spp., Shigella species, Campylobacter spp and Escherichia coli, were isolated using standard microbiological procedures. Stool samples were plated on Hektoen agar for the detection of Salmonella and Shigella, Eosin Methylene Blue and Uriselect for the detection of $E$. coli and on Karmali agar for the detection of Campylobacter. Plates were incubated at $37^{\circ} \mathrm{C}$, under specific microaerophilic conditions for Campylobacter (campygen, Oxoid, France). During the multicenter study, the plates positive for colonies suspected to be pathogenic Salmonella spp., Shigella species or E. coli and all Karmali agar plates were sent at least every 2 days to the Pasteur Institute for complete identification. Campylobacter spp. were confirmed with the hemagglutination test-kit (Campy dry spot, Oxoid, England), as recommended by the manufacturer.

Colonies typical of E. coli on EMB or Uriselect medium were further tested by PCR for genes encoding virulence factors associated with diarrheagenic E. coli [8].

\section{Susceptibility testing}

The antibiotic susceptibilities of all Salmonella, Shigella and diarrheagenic $E$. coli isolates were determined by a standard antibiotic disk diffusion technique according to 


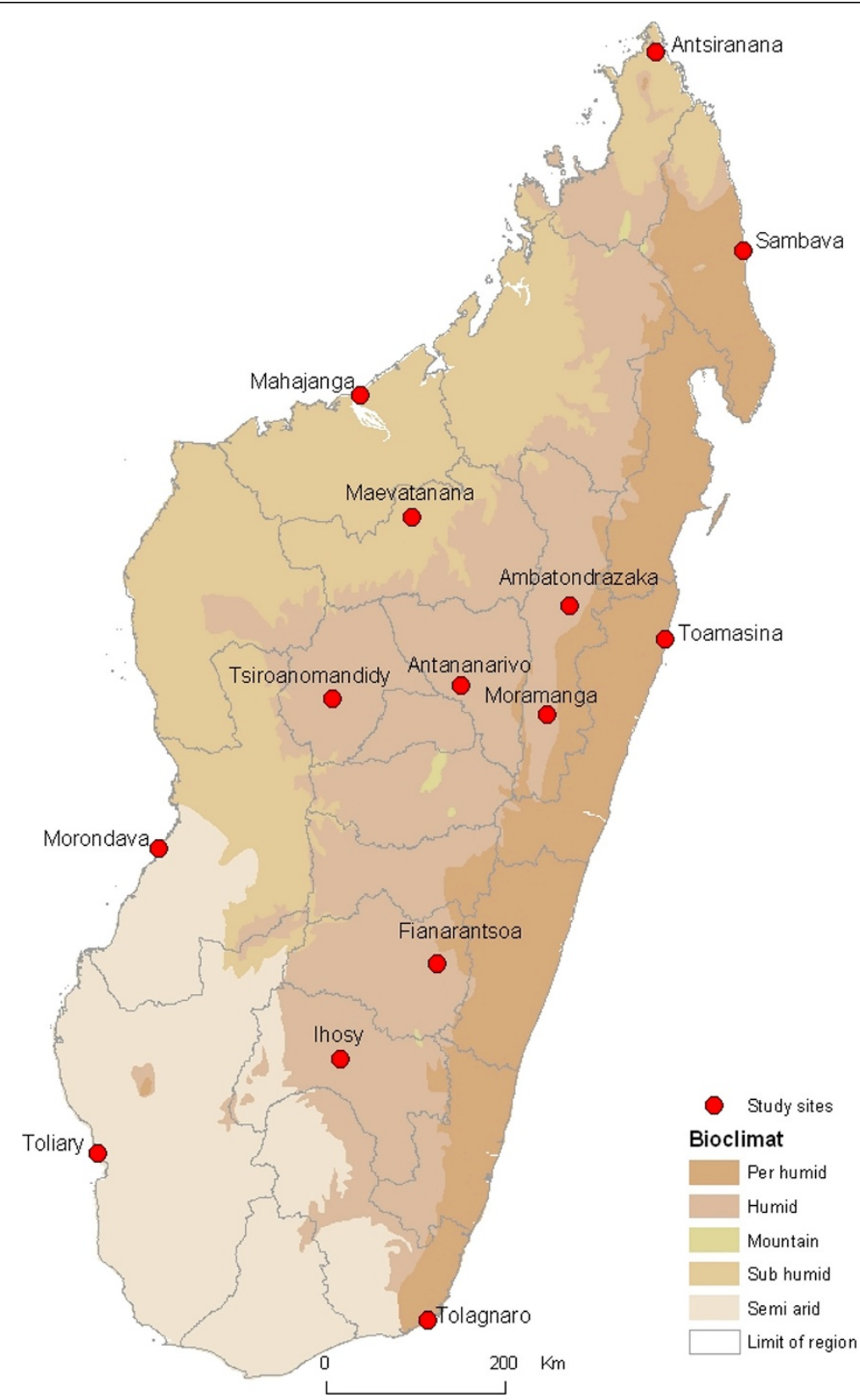

Figure 1 Map of Madagascar with the location of the sites where patients were enrolled during the multicenter study.

the Antibiogram Committee of the French Microbiology Society (CASFM) [9]. The antibiotics tested were nalidixic acid, ciprofloxacin, amoxicillin, amoxicillin + clavulanic acid, ticarcillin, ceftazidime, cefotaxime, cefoxitin, gentamicin and trimethoprim-sulfamethoxazole. Antimicrobial susceptibility was scored using the breakpoint criteria, as defined by the CASFM [9]. Extended Spectrum Betalactamase (ESBL) production was deduced from the resistance phenotype and results of the double-disk synergy test using conventional combinations (cefotaxime, ceftazidime, ceftriaxone $v s$. clavulanic acid) [10].
Escherichia coli ATCC 25922, Staphylococcus aureus ATCC 25923 and Pseudomonas aeruginosa ATCC 27853 were used as controls.

The minimum inhibitory concentrations (MICs) of five antimicrobial agents were determined for Campylobacter $s p$, using agar dilution methods. Two-fold serial dilutions of antibiotics were added to molten Mueller-Hinton II agar (Oxoid) supplemented with 5\% sheep blood at a temperature of $37^{\circ} \mathrm{C}$. The plates were seeded with $10^{4} \mathrm{cfu} / \mathrm{spot}$ of bacteria by means of a multipoint inoculator and incubated at $35^{\circ} \mathrm{C}$ under $\mathrm{CO}_{2}$ for $48 \mathrm{~h}$ in a microaerobic atmosphere (Campygen, Oxoid, France). 
The antimicrobials evaluated were ciprofloxacin, erythromycin, ampicillin, tetracycline and gentamicin. Reference strains Campylobacter coli ATCC 49941 and Campylobacter jejuni subsp jejuni ATCC 49943 were used as controls for both susceptibility testing and growth. The MIC breakpoints used were those recommended by the CASFM [9].

\section{Ethical issues}

The national Ethics Committee of Madagascar approved the research protocol. Informed consent was obtained from all the participants either directly or through their legal and competent guardians.

\section{Statistical analysis}

$\mathrm{R}$ software ( $\mathrm{R}$ Foundation for Statistical Computing, Vienna, Austria) was used for data analysis. In univariate analysis, the two-tailed Fisher's exact test was used to compare categorical variables for antibiotic resistance according to the study site (cross sectional community study or diagnostic activities of the Pasteur Institute of Madagascar). Factors identified by univariate analysis as being associated with $\mathrm{p}$-values $<0.20$ were retained for multivariate analysis. Differences were considered significant if the p-value was $<0.05$.

\section{Results}

Demographic characteristics of the patients included in the multicenter study were already given in a previous article; all patients were under 5 years old [6]. Concerning the patients presenting at the Pasteur Institute they were limited to age; the median age was 6 (range: 4 months - 82 years), and patients were divided in two groups (age $<5$ years old, $\mathrm{n}=81$ ) and patients $>=5$ years old, $\mathrm{n}=90$ ) for the analyses. Twenty-nine strains of Salmonella $s p$, 35 strains of Shigella sp, 195 strains of diarrheagenic E. coli, 203 strains of $C$. jejuni and 71 strains of $C$. coli, isolated from diarrheic and healthy children in the community [6], were tested for antibiotic resistance. Fifty-five strains of Salmonella $s p$ and 129 strains of Shigella $s p$ isolated from patients referred to the Pasteur Institute of Madagascar were included in the study. Among the Shigella isolates, 156 could be typed: there were 3 strains of S. boydii, 12 strains of S. dysenteriae, 99 strains of S. flexneri and 42 strains of S. sonnei.

Many of the Enterobacteriaceae were resistant to antibiotics widely used in Madagascar; in particular, resistance to penicillin A and trimethoprim-sulfamethoxazole was highly prevalent among Shigella and E. coli isolates (60\% to $80 \%$ of strains were resistant; Table 1), but less so among Salmonella sp (35.7 of the strains were resistant to amoxicillin and $2.3 \%$ to trimethoprim-sulfamathoxazole) (Table 1). There were no significant differences in rates of resistance between the different types of diarrheagenic $E$. coli.

Resistance to ampicillin and ticarcillin was significantly more prevalent among Salmonella strains isolated from patients referred to the Pasteur Institute of Madagascar (29 of 55 strains, $52.7 \%$ ) than among Salmonella strains isolated in the community (one of 29 strains, 3.5\%) ( $<<0.01$ ) (Table 2). Resistance to third generation cephalosporin was found only in one of 84 Salmonella strains (1.2\%) and six of 195 of diarrheagenic E. coli (3.1\%); all these resistant strains presented a ESBL phenotype (synergy between third generation cephalosporins and clavulanic acid and susceptibility to cefoxitin).

Significant differences in rates of resistance were also found between $S$. flexneri isolated from patients referred

Table 1 Susceptibility of Salmonella, Shigella sp and diarrheagenic Escherichia coli isolated from stools of patients with acute diarrhea, in Madagascar

\begin{tabular}{|c|c|c|c|c|c|c|c|c|c|}
\hline \multirow[b]{2}{*}{ Antimicrobial } & \multicolumn{3}{|c|}{ Salmonella $s p(n=84)$} & \multicolumn{3}{|c|}{ Shigella sp $(n=164)$} & \multicolumn{3}{|c|}{ Diarrheagenic $E$. coli $(n=195)$} \\
\hline & $\begin{array}{c}\text { Resistant } \\
\text { N (\%) }\end{array}$ & $\begin{array}{c}\text { Intermediate } \\
\text { (\%) }\end{array}$ & $\begin{array}{c}\text { Susceptible } \\
\text { (\%) }\end{array}$ & $\begin{array}{c}\text { Resistant } \\
\text { (\%) }\end{array}$ & $\begin{array}{c}\text { Intermediate } \\
\text { (\%) }\end{array}$ & $\begin{array}{c}\text { Susceptible } \\
\text { (\%) }\end{array}$ & $\begin{array}{c}\text { Resistant } \\
\text { (\%) }\end{array}$ & $\begin{array}{c}\text { Intermediate } \\
\text { (\%) }\end{array}$ & $\begin{array}{c}\text { Susceptible } \\
(\%)\end{array}$ \\
\hline Amoxicillin & $30(35.7)$ & $0(0.0)$ & $54(64.3)$ & $103(62.8)$ & $0(0.0)$ & $61(37.2)$ & $160(82.1)$ & $0(0.0)$ & $35(17.9)$ \\
\hline $\begin{array}{l}\text { Amoxicillin/Clavulanic } \\
\text { acid }\end{array}$ & $2(2.3)$ & $3(3.6)$ & $79(94.1)$ & $12(7.3)$ & $40(24.4)$ & $112(68.3)$ & $2(1.0)$ & $21(10.8)$ & $172(88.2)$ \\
\hline Ticarcillin & $30(35.7)$ & $0(0.0)$ & $54(64.3)$ & $102(62.2)$ & $1(0.6)$ & $61(37.2)$ & $161(82.6)$ & $0(0.0)$ & $34(17.4)$ \\
\hline Cephalothin & $2(2.3)$ & $3(3.6)$ & $79(94.1)$ & $14(8.5)$ & $37(22.5)$ & $113(69)$ & $6(3.1)$ & $11(5.6)$ & $178(91.3)$ \\
\hline Cefotaxime & $1(1.2)$ & $0(0.0)$ & $83(98.8)$ & $0(0.0)$ & $0(0.0)$ & $164(100)$ & $6(3.1)$ & $0(0.0)$ & $189(96.9)$ \\
\hline Ceftazidime & $1(1.2)$ & $0(0.0)$ & $83(98.8)$ & $0(0.0)$ & $0(0.0)$ & $164(100)$ & $3(1.5)$ & $3(1.5)$ & $189(96.9)$ \\
\hline Cefoxitin & $0(0.0)$ & $0(0.0)$ & $84(100)$ & $0(0.0)$ & $0(0.0)$ & $164(100)$ & $0(0.0)$ & $1(0.5)$ & $194(99.5)$ \\
\hline Gentamicin & $0(0.0)$ & $0(0.0)$ & $84(100)$ & $0(0.0)$ & $0(0.0)$ & $164(100)$ & $2(1.0)$ & $0(0.0)$ & 193 (99.0) \\
\hline Nalidixic acid & $1(1.2)$ & $2(2.3)$ & 81 (96.5) & $1(0.7)$ & $0(0.0)$ & $163(99.3)$ & $21(10.8)$ & $0(0.0)$ & $174(89.2)$ \\
\hline Ciprofloxacin & $0(0.0)$ & $0(0.0)$ & $84(100)$ & $0(0.0)$ & $0(0.0)$ & $164(100)$ & $6(3.1)$ & $0(0.0)$ & 189 (96.9) \\
\hline $\begin{array}{l}\text { Trimethoprim/ } \\
\text { Sulfamethoxazole }\end{array}$ & $2(2.3)$ & $0(0.0)$ & $82(97.7)$ & $131(79.9)$ & $5(3.0)$ & $28(17.1)$ & 165 (84.6) & $2(1.0)$ & $28(14.4)$ \\
\hline
\end{tabular}


Table 2 Percentage of isolates expressing resistance for Salmonella sp, Shigella flexneri and S. sonnei, according to the type of patient inclusion

\begin{tabular}{|c|c|c|c|c|c|c|c|c|c|c|c|c|}
\hline \multirow[t]{2}{*}{ Species } & \multirow{2}{*}{$\begin{array}{l}\text { Isolated from } \\
\text { (patient age) }\end{array}$} & \multirow{2}{*}{$\begin{array}{l}\text { Number } \\
\text { of strains }\end{array}$} & \multicolumn{2}{|c|}{$A m x$} & \multicolumn{2}{|c|}{ AMC } & \multicolumn{2}{|c|}{$\mathrm{CF}$} & \multicolumn{2}{|c|}{ TIC } & \multicolumn{2}{|c|}{ SXT } \\
\hline & & & $\bar{N}$ & $\overline{\%}$ & $\bar{N}$ & $\%$ & $\bar{N}$ & $\%$ & $\mathrm{~N}$ & $\%$ & $\mathrm{~N}$ & $\%$ \\
\hline \multirow[t]{4}{*}{ S. flexneri } & $\mathrm{PIM}^{*}(>=5$ years $)$ & 34 & 29 & (85) & 18 & (53) & 17 & (50) & 29 & $(85)$ & 24 & $\overline{(71)}$ \\
\hline & $\mathrm{PIM}(<5$ years $)$ & 39 & 36 & (92) & 25 & (69) & 25 & (69) & 36 & $(92)$ & 30 & $(77)$ \\
\hline & Transversal Study (<5 yrs) & 26 & 23 & (88) & 6 & (23) & 6 & (23) & 23 & (88) & 26 & $(100)$ \\
\hline & $p$-value & & \multicolumn{2}{|c|}{0.63} & \multicolumn{2}{|c|}{0.04} & \multicolumn{2}{|c|}{0.05} & \multicolumn{2}{|c|}{0.63} & \multicolumn{2}{|c|}{$<0.01$} \\
\hline \multirow[t]{4}{*}{ S. sonnei } & PIM (> = 5 years $)$ & 26 & 2 & (8) & 0 & $(0)$ & 0 & $(0)$ & 2 & (8) & 21 & $(81)$ \\
\hline & PIM (<5 years) & 13 & 1 & (8) & 0 & (0) & 0 & (0) & 1 & (8) & 13 & $(100)$ \\
\hline & Transversal study ( $<5$ yrs) & 3 & 2 & (67) & 0 & $(0)$ & 0 & (0) & 2 & $(67)$ & 3 & $(100)$ \\
\hline & $p$-value & & \multicolumn{2}{|c|}{0.03} & \multicolumn{2}{|c|}{-} & \multicolumn{2}{|c|}{ - } & \multicolumn{2}{|c|}{0.03} & \multicolumn{2}{|c|}{0.17} \\
\hline \multirow[t]{4}{*}{ Salmonella sp } & PIM (> = 5 years $)$ & 29 & 11 & (38) & 1 & (3) & 1 & (3) & 11 & (38) & 0 & $(0)$ \\
\hline & PIM ( $<5$ years) & 26 & 18 & (69) & 4 & $(15)$ & 4 & (15) & 18 & $(69)$ & 2 & (8) \\
\hline & Transversal study ( $<5$ yrs) & 29 & 1 & (3) & 0 & $(0)$ & 0 & $(0)$ & 1 & (3) & 1 & (3) \\
\hline & $p$-value & & \multicolumn{2}{|c|}{$<0.01$} & \multicolumn{2}{|c|}{0.04} & \multicolumn{2}{|c|}{0.04} & \multicolumn{2}{|c|}{$<0.01$} & \multicolumn{2}{|c|}{0.30} \\
\hline
\end{tabular}

*PIM: Pasteur Institute of Madagascar.

to the Pasteur Institute of Madagascar $(n=73)$ and $S$. flexneri isolated in the community $(\mathrm{n}=26)$ concerning trimethoprime-sulfamathoxazole ( $74 \%$ vs. $100 \%$ of strains being resistant, respectively, $\mathrm{p}<0.01$ ), nalidixic acid (57.5\% vs. $23 \%$, respectively, $\mathrm{p}<0.01$ ) and amoxicillin/ clavulanic acid $(58.9 \%$ vs. $23 \%$ respectively, $\mathrm{p}<0.01)$ (Table 2). There were differences in rates of resistance between S. flexneri and S. sonnei for amoxicillin and ticarcillin $(88.9 \%$ vs. $11.9 \%$ of strains were resistant, respectively, $\mathrm{p}<0.01)$, amoxicillin/clavulanic acid $(49.5 \%$ vs. $0 \%$, respectively, $\mathrm{p}<0.01)$ and cephalotin $(48.5 \%$ vs. $0 \%$, respectively, $\mathrm{p}<0.01)$. The only difference that persisted in multivariate analysis was the type of patient included in the study: at the Pasteur Institute of Madagascar or in the community (Tables 2 and 3). Among the patients referred to the Pasteur Institute of Madagascar, there was no difference between patients aged less than 5 years and those aged more than 5 years, except for resistance to ampicillin and ticarcillin in Salmonella; resistance to these drugs was more prevalent among Salmonella isolates from patients younger than 5 years old $(\mathrm{P}=0.04$ ) (Table 2).

There was a significant difference between the prevalence of resistance to ampicillin of $C$. jejuni and $C$. coli (66.5\% vs. $90.1 \%$, respectively, $\mathrm{p}<0.01, \mathrm{OR}=4.6,95 \% \mathrm{CI}$ [1.9-12.5]) (Table 4). The rates of resistance to other antibiotics, including tetracycline but excluding nalidixic acid, were low (Table 4).

In the multicenter study in the community, there was no significant difference in the rates of resistance to any antibiotic between isolates from cases and those from controls for any species, nor between isolates from different sites.

\section{Discussion}

Antibiotics are often used only as a supplemental tool to treat diarrhea, with oral rehydration being the main treatment. However, in developing countries where many children are malnourished, it may be advisable to use all tools to minimize the duration of the illness and avoid severe dehydration. In most areas of developing countries, bacterial identification is not feasible and hence the antibiogram for each patient cannot be determined. Therefore, extensive knowledge of the prevalence of antibiotic resistance among the various species involved would be extremely valuable. Our study presents the strength of having been conducted in 14 different sites in Madagascar (Figure 1). It is therefore representative of the whole country, at least for diarrheagenic E. coli and Campylobacter sp. We chose also to include Salmonella and Shigella strains isolated at the Pasteur

Table 3 Percentage of susceptible and intermediately susceptible (in brackets) isolates of the Shigella genera

\begin{tabular}{lcccccccccccc}
\hline Pathogens (No tested) & AMX & AMC & TIC & CF & FOX & CTX & CAZ & NA & CIP & GM & SXT \\
\hline Shigella species (8) & 37.5 & $75(25)$ & 37.5 & $75(25)$ & 100 & 100 & 100 & 87.5 & 100 & 100 & $0(12.5)$ \\
S. dysenteriae (12) & 66.7 & $91.7(8.3)$ & 66.7 & $91.7(8.3)$ & 100 & 100 & 100 & 100 & 100 & 100 & 33.3 \\
S. flexneri (99) & 11.1 & $50.5(37.4)$ & $11.1(1)$ & $50.5(37.4)$ & 100 & 100 & 100 & 100 & 100 & 100 & $19.2(4)$ \\
S. boydii (3) & 66.7 & 100 & 66.7 & 100 & 100 & 100 & 100 & 100 & 100 & 100 & 0 & 100 \\
S. sonnei (42) & 88.1 & 100 & 88.1 & 100 & 100 & 100 & 100 & 100 & 100 & 100 & 11.9 \\
\hline
\end{tabular}


Table 4 Susceptibility of Campylobacter sp isolated from stools of patients with acute diarrhea, in Madagascar

\begin{tabular}{|c|c|c|c|c|c|c|c|c|c|c|c|c|}
\hline & \multicolumn{6}{|c|}{ C. jejuni } & \multicolumn{6}{|c|}{ C. coli } \\
\hline & \multicolumn{2}{|c|}{ Susceptible } & \multicolumn{2}{|c|}{ Intermediate } & \multicolumn{2}{|c|}{ Resistant } & \multicolumn{2}{|c|}{ Susceptible } & \multicolumn{2}{|c|}{ Intermediate } & \multicolumn{2}{|c|}{ Resistant } \\
\hline & $n$ & $\%$ & $n$ & $\%$ & $n$ & $\%$ & $n$ & $\%$ & $\mathrm{n}$ & $\%$ & $n$ & $\%$ \\
\hline Erythromycin & 160 & $(78.8)$ & 41 & (20.2) & 2 & $(1.0)$ & 50 & $(70.4)$ & 18 & $(25.4)$ & 3 & (4.2) \\
\hline Ampicillin & 68 & (33.5) & 95 & $(46.8)$ & 40 & $(19.7)$ & 7 & (9.9) & 36 & $(50.7)$ & 28 & (39.4) \\
\hline Gentamycin & 202 & $(99.5)$ & 1 & $(0.5)$ & 0 & $(0.0)$ & 71 & $(100.0)$ & 0 & $(0.0)$ & 0 & $(0.0)$ \\
\hline Tetracycline & 201 & $(99.0)$ & 0 & $(0.0)$ & 2 & $(1.0)$ & 70 & (98.6) & 0 & $(0.0)$ & 1 & (1.4) \\
\hline Ciprofloxacin & 199 & $(98.0)$ & 2 & $(1.0)$ & 2 & $(1.0)$ & 67 & (94.4) & 0 & $(0.0)$ & 4 & (5.6) \\
\hline
\end{tabular}

Institute of Madagascar to increase the scope of the study. This may have introduced a bias, but any such bias is probably minor because many of patients presenting at the Pasteur Institute of Madagascar for diarrhea had traveled in the country immediately before the onset of symptoms such that the strains isolated did not all originate from Antananarivo. The age of patients is also different but differences are mainly between patients presenting at the Pasteur Institute, whatever their age, and those enrolled in the transversal study.

The prevalence of resistance of Shigella and E. coli to ampicillin and cotrimoxazole were very high, and much higher than those of Salmonella sp. They were similar to the rates of resistance of $E$. coli isolated from urinary tract infections in a previous study [11]. These rates of resistance to ampicillin and cotrimoxazole are also similar to those observed in Botswana and Kenya, where the differences in rates of resistance between Salmonella and Shigella have also been reported [12,13]. During a previous survey conducted in 1988-1989 in Madagascar, rates of resistance of Shigella were different from those we report here [5]. Resistance of $S$. dysenteriae to ampicillin and cotrimoxazole were slightly more prevalent in the previous study (69\% vs. $63 \%$ and $38 \%$ vs. $0 \%$, respectively) whereas resistance of $S$. flexneri to penicillin A and cotrimoxazole have become considerably more prevalent since 1989 (13\% vs. $89 \%$ and $4.3 \%$ vs. $80 \%$, respectively). In our study, no resistance to ciprofloxacin was found in Salmonella or Shigella isolates, in contrast to what has been described elsewhere, for example on the Andaman Islands [14]. However, according to the CASFM, strains of Salmonella resistant or intermediately resistant to nalidixic acid should be categorized as resistant to fluoroquinolones [9]. Therefore three strains in our study should be considered as resistant to ciprofloxacin.

Nevertheless, few of the diarrheagenic E. coli isolates were resistant to ciprofloxacin (3.1\%).

ESBL-producing E. coli were detected but the rates were lower than those of rectal carriage of ESBLproducing $E$. coli observed both in community settings in Madagascar (6.4\%) [15], and in children on admission to a pediatric unit in Antananarivo (10\%) [16]. This rate was, however, similar to what was observed for E. coli isolated from urinary tract infections in the community [11]. The rates of ESBL-producing E. coli were also lower than that observed in Cairo, Egypt (14.3\%) [17], but higher than in South America where rates of resistance to ampicillin and cotrimoxazole are high whereas no resistance to third generation cephalosporin has been observed in Brazil or Peru [18,19].

Rates of resistance among Campylobacter $s p$ were similar to that found in 2005 for isolates from chickens in Antananarivo [20]. The only major difference was that resistance to erythromycin was less prevalent in our (5/ $274,2 \%)$ than the previous study $(18.3 \%$ of resistant strains).

The resistance of Campylobacter $s p$ to antibiotics frequently used for therapy in veterinary medicine in many countries (tetracycline and ciprofloxacin) was much lower in our study than reported in most other studies [21-24]. It is likely that antibiotics are too expensive for most farmers in Madagascar, and this would explain the susceptibility of most strains in the country.

Rates of resistance were similar in diarrheic and healthy children which is not surprising since strains were probably clonally related in a village. This is also compatible with the fact that the prevalence rates were not different for all these strains between diarrheic and healthy children [6].

In a previous article, we described the types of pathogens detected in this study, and reported that intestinal pathogens were the most frequently encountered. Giardia lamblia, Trichomonas intestinalis and Entamoeba histolytica were the only pathogens that were detected at a higher frequency in patients with diarrhea than in patients without diarrhea [6]. These results and those of our antimicrobial susceptibility study argue strongly for a reasoned use of antibiotics to treat diarrhea in children in Madagascar. Indeed, other than Salmonella, which are rarely isolated and for which antibiotics are not recommended, the most common enterobacteria (Shigella and E. coli) isolated from such patients are resistant to penicillin A and cotrimoxazole in nearly four of every five cases. The only available antibiotic that can be 
administered orally and likely to be effective is ciprofloxacin which is not recommended in children.

\section{Conclusions}

Our study shows a high prevalence of antimicrobial resistance to ampicillin and trimethoprim/sulfamethoxazole. These results and the fact that parasites are frequently responsible for diarrhea in Malagasy children imply that antibiotic treatment is not recommended for children with diarrhea in Madagascar. Therefore, we believe that emphasis should be placed on the importance of oral rehydration in the management of diarrhea in children in Madagascar.

\section{Competing interests}

The authors declare that they have no competing interests.

\section{Authors' contribution}

$F R, E R H, L R, R R, S R$ participated in the field study and the patients recruitment. FR, ERH, LR, HCT, TA, FR and AT paricipated in the antibiotic susceptibility testing. VR realised the statistical analysis. FR, ERH, VR ansd AT participated in the study design. FR, ERH, LR, VR and AT participated to the redaction of the article. All authors read and approved the final manuscript.

\section{Acknowledgments}

We thank the staff of the districts for their assistance during the study, and the population of the villages for their welcome. We are grateful to Dr. Philippe Sansonetti from the Pasteur Institute in Paris and the Total foundation for their support for research on diarrhea.

\section{Author details}

${ }^{1}$ Clinical Biology Center, Institut Pasteur de Madagascar, Antananarivo, Madagascar. ${ }^{2}$ Epidemiologic Unit, Institut Pasteur de Madagascar, Antananarivo, Madagascar. ${ }^{3}$ Molecular Biology Unit, Institut Pasteur de Madagascar, Antananarivo, Madagascar. ${ }^{4}$ Institut Pasteur de Madagascar Antananarivo, Madagascar.

Received: 26 June 2013 Accepted: 10 February 2014 Published: 25 February 2014

\section{References}

1. Kosek M, Bern C, Guerrant RL: The global burden of diarrhoeal disease, as estimated from studies published between 1992 and 2000. Bull World Health Organ 2003, 81:197-204.

2. Boschi-Pinto C, Velebit L, Shibuya K: Estimating child mortality due to diarrhoea in developing countries. Bull World Health Organ 2008, 86:710-717.

3. Guerrant RL, Van Gilder T, Steiner TS, Thielman NM, Slutsker L, Tauxe RV, Hennessy T, Griffin PM, DuPont H, Sack RB, Tarr P, Neill M, Nachamkin I, Reller LB, Osterholm MT, Bennish ML, Pickering LK: Infectious Diseases Society of America. Practice guidelines for the management of infectious diarrhea. Clin Infect Dis 2001, 32:331-351.

4. American Medical Association, Centers for Disease Control and Prevention, Center for Food Safety and Applied Nutrition, Food and Drug Administration, Food Safety and Inspection Service, US Department of Agriculture: Diagnosis and management of foodborne illnesses: a primer for physicians. MMWR Recomm Rep 2001, 50(RR-2):1-69.

5. Cassel-Béraud AM, Coulanges P, Richard C, Vaslet I: Antibiotic resistance of strains of Shigella dysenteriae and flexneri isolated in Tananarive and on the east coast of Madagascar. Bull Soc Pathol Exot 1990, 83:31-36.

6. Randremanana R, Randrianirina F, Gousseff M, Dubois N, Razafindratsimandresy R, Hariniana ER, Garin B, Randriamanantena A Rakotonirina HC, Ramparany L, Ramarokoto CE, Rakotomanana F, Ratsitorahina M, Rajatonirina S, Talarmin A, Richard V: Case-control study of the etiology of infant diarrheal disease in 14 districts in Madagascar. PLoS One 2012, 7:e44533.

7. World Health Organization: WHO/UNICEF Joint Statement, Clinical Management of Acute Diarrhoea. Geneva: World Health Organization; 2004:1-8.

8. Müller D, Greune L, Heusipp G, Karch H, Fruth A, Tschäpe H, Schmidt MA: Identification of unconventional intestinal pathogenic Escherichia coli isolates expressing intermediate virulence factor profiles by using a novel single-step multiplex PCR. Appl Environ Microbio/ 2007, 73:3380-3390.

9. Comité de l'Antibiogramme de la Société Française de Microbiologie: Recommandations 2013. Paris, France: SFM; 2012

10. Legrand P, Fournier G, Bure A, Jarlier V, Nicolas MH, Decre D, Duval J, Philippon A: Detection of extended broad-spectrum beta-lactamases in Enterobacteriaceae in four French hospitals. Eur J Clin Microbiol Infect Dis 1989, 8:527-529.

11. Randrianirina F, Soares $J$, Carod JF, Ratsima E, Thonnier V, Combe P, Grosjean P, Talarmin A: Antimicrobial resistance among uropathogens that cause community-acquired urinary tract infections in Antananarivo, Madagascar. J Antimicrob Chemother 2007, 59:309-312.

12. Rowe JS, Shah SS, Motlhagodi S, Bafana M, Tawanana E, Truong HT, Wood SM, Zetola NM, Steenhoff AP: An epidemiologic review of enteropathogens in Gaborone, Botswana: shifting patterns of resistance in an HIV endemic region. PLOS One 2010, 5:e10924.

13. Shapiro RL, Kumar L, Phillips-Howard P, Wells JG, Adcock P, Brooks J, Ackers ML, Ochieng JB, Mintz E, Wahlquist S, Waiyaki P, Slutsker L: Antimicrobialresistant bacterial diarrhea in rural western Kenya. J Infect Dis 2001, 183:1701-1704.

14. Bhattacharya D, Sugunan AP, Bhattacharjee $H$, Thamizhmani $R$, Sayi DS, Thanasekaran K, Manimunda SP, Ghosh AR, Bharadwaj AP, Singhania M, Roy S: Antimicrobial resistance in Shigella-rapid increase \& widening of spectrum in Andaman Islands, India. Indian J Med Res 2012, 135:365-370.

15. Herindrainy $P$, Randrianirina F, Ratovoson R, Ratsima Hariniana E, Buisson $Y$ Genel N, Decré D, Arlet G, Talarmin A, Richard V: Rectal carriage of extended-spectrum Beta-lactamase-producing gram-negative bacilli in community settings in Madagascar. PLoS One 2011, 6:e22738.

16. Andriatahina T, Randrianirina F, Hariniana ER, Talarmin A, Raobijaona $H_{4}$ Buisson Y, Richard V: High prevalence of fecal carriage of extendedspectrum beta-lactamase-producing Escherichia coli and Klebsiella pneumoniae in a pediatric unit in Madagascar. BMC Infect Dis 2010, 10:204.

17. Behiry IK, Abada EA, Ahmed EA, Labeeb RS: Diarrheagenic Escherichia coli associated with diarrhea in children in Cairo, Egypt. Sci World J 2011, 11:2613-2619

18. Garcia PG, Silva VL, Diniz CG: Occurrence and antimicrobial drug susceptibility patterns of commensal and diarrheagenic Escherichia coli in fecal microbiota from children with and without acute diarrhea. J Microbiol 2011, 49:46-52.

19. Ochoa TJ, Ruiz J, Molina M, Del Valle L, Vargas M, Gil Al, Ecker L, Barletta F, Hall E, Cleary TG, Lanata CF: High frequency of antimicrobial drug resistance of diarrheagenic Escherichia coli in infants in Peru. Am J Trop Med Hyg 2009, 81:296-301.

20. Garin B, Gouali M, Wouafo M, Perchec AM, Pham MT, Ravaonindrina N, Urbès F, Gay M, Diawara A, Leclercq A, Rocourt J, Pouillot R: Prevalence, quantification and antimicrobial resistance of Campylobacter spp. on chicken neck-skins at points of slaughter in 5 major cities located on 4 continents. Int J Food Microbiol 2012, 157:102-107.

21. Goualie Gblossi B, Akpa EE, Kakou-N'Gazoa ES, Guessennd N, Bakayoko S, Niamke LS, Dosso M: Prevalence and antimicrobial resistance of thermophilic campylobacter isolated from chicken in Côte d'Ivoire. Int $J$ Microbiol 2012, 2012:150612.

22. Rozynek E, Dzierzanowska-Fangrat K, Szczepańska B, Wardak S, Szych J, Konieczny P, Albrecht P, Dzierzanowska D: Trends in antimicrobial susceptibility of Campylobacter isolates in Poland (2000-2007). Pol J Microbiol 2009, 58:111-115.

23. Gallay A, Prouzet-Mauléon V, Kempf I, Lehours P, Labadi L, Camou C, Denis $M$, de Valk H, Desenclos JC, Mégraud F: Campylobacter antimicrobial drug resistance among humans, broiler chickens, and pigs, France. Emerg Infect Dis 2007, 13:259-266.

24. Zhao S, Young SR, Tong E, Abbott JW, Womack N, Friedman SL, McDermott PF: Antimicrobial resistance of Campylobacter isolates from retail meat in the United States between 2002 and 2007. Appl Environ Microbiol 2010, 76:7949-7956.

\section{doi:10.1186/1471-2334-14-104}

Cite this article as: Randrianirina et al:: Antimicrobial resistance of bacterial enteropathogens isolated from stools in Madagascar. BMC Infectious Diseases 2014 14:104. 